\title{
Reviewing Guidelines on Diabetic Retinopathy Screening in Children and Adolescents with Type 1 Diabetes: Is there consistency amongst practitioners?
}

\author{
Katherine Xiaoke Li, MD., Bachelor of Honours Health Sciences, Western University, London, Ontario \\ Marge Lovell, RN, MEd; Children's Hospital, London Health Sciences Centre, London, Ontario \\ Keira Evans, RN, MScN, CDE; Children's Hospital at London Health Sciences Centre, London, Ontario \\ Patricia H. Gallego, MD FRACP PhD; Assistant Professor at Schulich School of Medicine, Western University; \\ and Pediatric Endocrinologist at Children's Hospital , London Health Sciences Centre, London, Ontario \\ Correspondence may directed to: keira.evans@lhsc.on.ca
}

\begin{abstract}
Diabetic retinopathy (DR) is a common eye disease and a leading cause of visual impairment in patients with Type 1 diabetes (T1DM). Retinopathy screening for T1DM varies according to the age of disease onset and diabetes duration. Retinal screening varies from standard fundal examination to more advanced methods of screening. An online survey was conducted in February 2014. The purpose of this survey was to assess the frequency and methods of eye examinations routinely performed in children and adolescents with T1DM. Data on local practices were collected from a group of optometrists and ophthalmologists in the London-Middlesex area. One hundred and one surveys were e-mailed out and the response rate was $37.6 \%$. Results indicated that different screening methods vary according to individual practices. These results may have an impact on the findings of retinopathy in this population. A review of utilized screening methods and comparisons to established guidelines will be highlighted.
\end{abstract}

Keywords: diabetic retinopathy; type 1 diabetes; children; microvascular complications.

\section{Résumé}

La rétinopathie diabétique est une maladie oculaire répandue et une cause importante de déficience visuelle chez les personnes atteintes de diabète de type 1 . Son dépistage varie suivant l'âge du patient quand le diabète est diagnostiqué et l'ancienneté de cette maladie. Les méthodes de dépistage vont du simple examen du fond d'œil à des techniques plus poussées. En février 2014, nous avons mené un sondage en ligne, afin d'évaluer la fréquence et la nature des examens oculaires menés systématiquement chez les enfants et les adolescents atteints de diabète de type 1. Les données sur les pratiques locales ont été recueillies chez des optométristes et des ophtalmologistes de la région de London-Middlesex (Ontario). Le taux de réponse aux 101 formulaires envoyés par courriel s'est établi à 37,6\%. Les résultats obtenus témoignent de la diversité des méthodes de dépistage appliquées par les praticiens. Cette diversité pourrait avoir une incidence sur le diagnostic de la rétinopathie chez les enfants et les adolescents diabétiques. Cet article expose les méthodes de dépistage appliquées, en les mettant en parallèle avec les méthodes recommandées dans les lignes directrices établies.

Mots clés : rétinopathie diabétique; diabète de type 1; enfants; complications microvasculaires. 


\section{Introduction}

In 2008/09, more than 3,000 new cases of diabetes (Type 1 and Type 2) were reported among Canadian children and youth aged one to 19 years, bringing the number of prevalent cases to just fewer than 26,000 . The rate of T1DM diabetes among one to nine year olds has increased, from $0.1 \%$ (3,726 cases) in $1998 / 99$ to $0.2 \%$ (5,201 cases) in 2008/09. ${ }^{1}$ Despite the increase in incidence, the prevalence of diabetic retinopathy (DR) has decreased globally, which is mainly attributed to improved management of diabetes control. ${ }^{2}$ In a 20-year Australian study of 1604 adolescents with T1DM, it was found that the prevalence of DR was approximately $50 \%$ in the early 1990 s, and decreased to approximately $12 \%$ in $2009 .^{3}$

The Diabetes Control and Complications Trial (DCCT, 1983-1993) $)^{4}$ provided unequivocal evidence that intensive diabetes treatment and improved glycemic control conferred a significant risk reduction for microvascular complications compared with conventional treatment. In the adolescent cohort, intensive treatment compared with conventional treatment reduced the risk and progression of background retinopathy by $53 \% .{ }^{4}$ Diabetic retinopathy rarely develops in children with Type 1 diabetes $<10$ years of age regardless of the duration of diabetes. Among patients $<15$ years of age, irrespective of age of diabetes onset, the prevalence of mild nonproliferative retinopathy was $2 \%$ with no reported sightthreatening diabetic retinopathy. ${ }^{2}$ However, the prevalence rate increases sharply after 5 years' duration of diabetes in post pubertal individuals with Type 1 diabetes. ${ }^{2}$ Early identification and treatment of DR can decrease the risk of vision loss in affected patients. Therefore, it is imperative to screen for early signs of this complication in the pediatric T1DM population.

There are three distinct forms of DR: i) macular edema, ii) nonproliferative and proliferative $\mathrm{DR}$, and iii) retinal capillary closure. Macular edema involves focal or diffuse vascular leakage at the site of the macula. Nonproliferative DR is the progressive accumulation of blood vessel change that includes microaneurysms, intraretinal hemorrhage, vascular tortuosity and vascular malformation (together known as nonproliferative diabetic retinopathy) that ultimately leads to abnormal vessel growth (proliferative diabetic retinopathy). Retinal capillary closure is a form of vascular change detected on fluorescein angiography, which is also well recognized as a potentially blinding complication of diabetes but currently has no treatment options. ${ }^{5}$ Severe nonproliferative DR, proliferative DR, and clinically significant macular edema are considered sight-threatening DR.

The aim of this survey was to explore the practices for DR screening in patients with T1DM aged less than 18 years assessed in London Middlesex County, Ontario. Screening methods in relation to recommended guidelines will be discussed.

\section{Methods}

The online survey was approved by the Ethics Review Board of Western University (\#HSREB 104566). Questionnaires were distributed by e-mail to optometrists and ophthalmologists in London and Middlesex County listed in the Optometry Association of Ontario. This was conducted via Survey Monkey from February 10th, 2014 to March 1st, 2014. Participants were advised that by opening the electronic survey and completing it, they were providing their consent to be involved in the study.

Seven open-ended questions were administered to all participants Table 1. Questions on the survey were related to the frequency and technique of eye examinations routinely performed in T1D children. Responses were collected for review and analysis.

\section{Results}

Responses were received from 38 of 101 surveys sent (response rate $37.6 \%$ ), which included 31 optometrists and 7 ophthalmologists $(81.6 \%$ and $18.4 \%$, respectively). All responding optometrists and 6 out of 7 ophthalmologists examine children or adolescents aged less than 18 years with T1DM for DR. From the optometrist group, the majority (64.5 $\%$ ) examine less than 10 children and adolescents per year. From the ophthalmology group, the majority (57\%) examine more than 10 patients per year.

Respondents use different methods to screen for DR as shown in Figure 1. A subgroup of respondents (28\%) examines for DR using multiple methods Figure 2.

The majority of optometrists (96.8\%) and ophthalmologists (71.4\%) recommend annual eye exams for children and adolescents with T1DM if their exam is normal. One optometrist (3.2\%) recommends exams every two years, and two ophthalmologists $(28.6 \%)$ recommend exams every 6 months.

In terms of referring patients for an ophthalmologist assessment, a higher percentage of optometrists (54.8\%) refer those with signs of moderate non-proliferative diabetic retinopathy (NPDR). Two (6.5\%) ophthalmologists refer with findings of mild NPDR and six (19.4\%) refer only if evidence of severe NPDR. $19.3 \%$ refer children with T1DM only with evidence of proliferative diabetic retinopathy (either early or high risk).

All ophthalmologists and 53\% of optometrists send reports to both the family doctor and the endocrinologist; $38 \%$ of optometrists send reports to the family doctor only and 3\% do not send any reports. 
Table 1. Eye Survey Questions

1. Do you assess patients with diabetes for diabetes retinopathy? Y/N

2. Do you exam children/adolescents aged less than 18 years with Type 1 diabetes? $\mathrm{Y} / \mathrm{N}$

3. Approximately, how many children/ adolescents aged less than 18 years with type 1 diabetes do you exam per year?

(Age groups: $<5,5-10,10-15,15-20)$

4. What is the method of screening used for the population with type 1 diabetes?

a) Ophthalmoscopy without dilated fundi

b) Ophthalmoscopy on dilated fundi

c) 7-field stereoscopic photography with pupil dilation

d) 4-field wide-angle stereoscopic photography with pupil dilation

e) Digital imaging (3-field) with no dilation

f) Other method, please

specify:

5. If the eye exam is NORMAL, how frequently do you recommend eye exam for children and adolescents with type 1 diabetes?
a) 6 months
b) 12 months
c) 24 months
d) $>24$ months

6. If you are not an ophthalmologist, what abnormalities according to Airlie House classification for diabetic retinopathy do you refer children/ adolescents with type 1 diabetes to an ophthalmologist?
a) Mild nonproliferative
b) Moderate nonproliferative
c) Severe nonproliferative
d) Early proliferative retinopathy
e) High risk proliferative retinopathy

7. To whom do you send the eye examination reports?

a) To Family doctor

b) To Endocrinologist

c) To both Family doctor and endocrinologist

d) To family only

e) Reports not sent

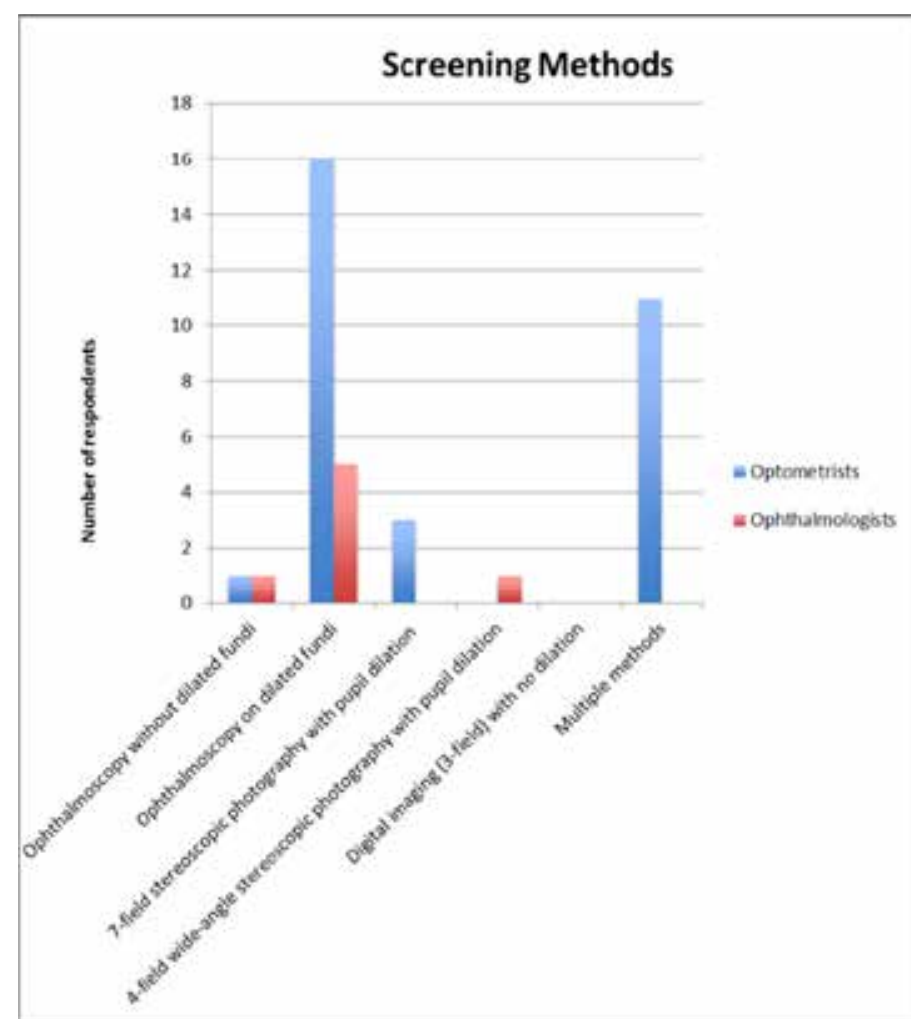

Figure 1. Methods for assessment of diabetic retinopathy (DR) used among children and adolescents with type 1 diabetes (T1DM).

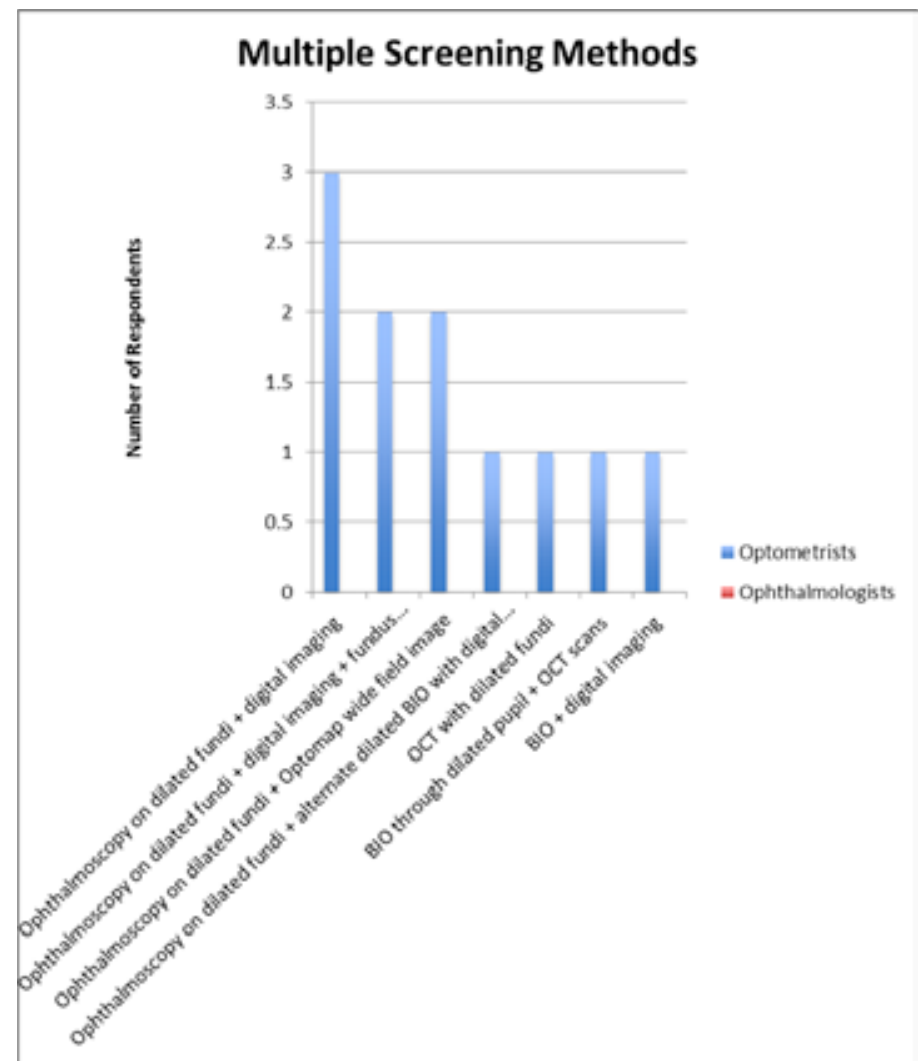

Figure 2. Distribution of multiple screening methods used in examining children and adolescents with type 1 diabetes (T1DM). 
Table 2. Summary of screening methods for diabetic retinopathy

\begin{tabular}{|c|c|c|c|}
\hline Screening Method & Description & Sensitivity & Specificity \\
\hline \multicolumn{4}{|c|}{ Methods done with pupil dilation } \\
\hline $\begin{array}{l}\text { 7-field stereoscopic } \\
\text { photography }\end{array}$ & \multicolumn{3}{|c|}{$\begin{array}{l}\text { Film photographs of the retina taken at } 30^{\circ}-35^{\circ} \text { fields. Gold standard for documenting diabetic retinopathy as described in } \\
\text { the Early Treatment Diabetic Retinopathy Study. } .^{12}\end{array}$} \\
\hline $\begin{array}{l}\text { 4-field wide-angle } \\
\text { stereoscopic photography }\end{array}$ & $\begin{array}{l}\text { Digital coloured images of the retina taken at } 45^{\circ}-60^{\circ} \\
\text { fields. }{ }^{13}\end{array}$ & $\begin{array}{l}94 \% \text { for detecting severe } \\
\text { NPDR or better }\end{array}$ & $\begin{array}{l}96 \% \text { for detecting severe NPDR } \\
\text { or better }\end{array}$ \\
\hline $\begin{array}{l}\text { Ophthalmoscopy with pupil } \\
\text { dilation }\end{array}$ & $\begin{array}{l}\text { Clinical examination of the retina using } \\
\text { ophthalmoscope through dilated pupil. }\end{array}$ & $65 \%$ (95\% Cl: $51-79 \%)$ & $97 \%(95 \% \mathrm{Cl}: 95-99 \%)$ \\
\hline Fundus biomicroscopy & $\begin{array}{l}\text { Slit-lamp examination with use of biomicroscope to } \\
\text { provide stereoscopic, highly magnified examination } \\
\text { of the ocular fundus and vitreous with a large field } \\
\text { of view. It should be considered the standard clinical } \\
\text { technique for stereoscopic examination of the posterior } \\
\text { pole of the eye. }{ }^{14}\end{array}$ & $\begin{array}{l}76 \%(95 \% \mathrm{Cl}: 70-81 \%) \text { for } \\
\text { detecting sight threatening DR }\end{array}$ & $\begin{array}{l}\text { 95\% (95\% Cl: } 95-96 \%) \text { for } \\
\text { detecting sight threatening DR }\end{array}$ \\
\hline \multicolumn{4}{|c|}{ Methods done without pupil dilation } \\
\hline $\begin{array}{l}\text { Ophthalmoscopy without } \\
\text { pupil dilation }\end{array}$ & $\begin{array}{l}\text { Clinical examination of the retina using } \\
\text { ophthalmoscope without dilation of pupil. }\end{array}$ & Not available & Not available \\
\hline $\begin{array}{l}\text { Digital imaging (3-field) } \\
\text { without pupil dilation }\end{array}$ & $\begin{array}{l}\text { Three } 45^{\circ} \text { field stereoscopic fundus images obtained at } \\
\text { the optic disc and macula, superotemporal to the optic } \\
\text { disc, and nasal to the optic disc. }{ }^{15}\end{array}$ & $98 \%$ & $86 \%$ \\
\hline $\begin{array}{l}\text { Binocular indirect } \\
\text { ophthalmoscopy (BIO) }\end{array}$ & $\begin{array}{l}\text { Headband or Slit-lamp examination using a BIO lens. } \\
\text { The slit lamp microscope binocular indirect method } \\
\text { allows for assessment of the depth of retinal vascular } \\
\text { lesions, disc evaluation and macular oedema. The } \\
\text { head-band indirect } \\
\text { ophthalmoscopy method allows for views into the far } \\
\text { periphery, past the equator. }{ }^{16}\end{array}$ & $76 \%$ & $95 \%$ \\
\hline Optomap wide field image & $\begin{array}{l}\text { One stereoscopic digital image taken at up to } \\
200^{\circ}(82 \%) \text { of the retina, using scanning laser } \\
\text { ophthalmoscope technology combined with a large } \\
\text { ellipsoidal mirror. }{ }^{17}\end{array}$ & $\begin{array}{l}\text { DR: } 99 \% \\
\text { DR: } 99 \%\end{array}$ & $\begin{array}{l}\text { DR: } \\
100 \% \\
\text { PDR: } 99 \%\end{array}$ \\
\hline
\end{tabular}

$\mathrm{Cl}$, confidence interval

\section{Discussion}

Diabetic retinopathy rarely develops in children with Type 1 diabetes $<10$ years of age regardless of the duration of diabetes. ${ }^{2}$ In the Wisconsin Epidemiology Study of Diabetic Retinopathy 4 -year incidence study, no person $<17$ years of age developed proliferative retinopathy or macular edema. ${ }^{2}$ In the United Kingdom Prospective Diabetes Study (UKPDS), few patients without retinopathy at diagnosis of diabetes had disease progression to the point of requiring retinal photocoagulation (laser treatment) in the following 3 to 6 years. ${ }^{6}$

The Liverpool Diabetic Eye Study reported the 1-year cumulative incidence of sight-threatening diabetic retinopathy in individuals with Type 1 or Type 2 diabetes who, at baseline, had no diabetic retinopathy, had background retinopathy or had mild pre-proliferative retinopathy. In people with Type 1 diabetes, the incidence in these groups was $0.3 \%, 3.6 \%$ and $13.5 \%$, respectively. ${ }^{7}$

In the pediatric population with Type 1 diabetes, others have reported a decline in retinopathy supporting current guidelines that recommend lower glycemic targets and the use of intensive diabetes management in children and adolescents with T1DM. ${ }^{3}$

In a cross-sectional study, Kubin et al (2011) examined the prevalence of DR through fundus photographs in children and adolescents diagnosed with T1DM. The overall prevalence of DR was $11.8 \%$ showing no decrease in the past 17 years. ${ }^{8}$

The largest prospective studies to date by Porta et al (2014) support the hypotheses that DR may appear later in patients 
Table 3. Summary of recommended guidelines for Diabetic Retinopathy screening

\begin{tabular}{|c|c|c|c|}
\hline $\begin{array}{l}\text { Guideline } \\
\text { recommendations }\end{array}$ & Initiate screening & Frequency of screening & Method of screening \\
\hline ISPAD/IDF'-10 & $\begin{array}{l}\text { Start screening for retinopathy at age } \\
11 \text { and after } 2 \text { years of type } 1 \text { diabetes } \\
\text { duration. }\end{array}$ & $\begin{array}{l}\text { Screen annually after } 2 \text { to } 5 \text { years' } \\
\text { diabetes duration and more } \\
\text { frequently if indicated. } \\
\text { For those with less than } 10 \\
\text { years of diabetes duration, with } \\
\text { reasonable glycemic control } \\
\text { may assess biennially by fundal } \\
\text { photography. }\end{array}$ & $\begin{array}{l}\text { Minimum retinopathy assessment should } \\
\text { be by ophthalmoscopy through dilated } \\
\text { pupils by an experienced observer. } \\
\text { In countries with ample resources, } \\
\text { retinopathy assessment should be by } \\
\text { fundal photography with or without } \\
\text { mydriasis. }\end{array}$ \\
\hline CDA $2013^{6}$ & $\begin{array}{l}\text { Start screening for retinopathy } 5 \text { years } \\
\text { after type } 1 \text { diagnosis in all individuals } \\
15 \text { years and older }\end{array}$ & $\begin{array}{l}\text { Five years after diagnosis of type } \\
1 \text { diabetes in all individuals } \geq 15 \\
\text { years, rescreen annually. }\end{array}$ & $\begin{array}{l}\text { Seven-standard field, stereoscopic colour } \\
\text { fundus photography with interpretation by } \\
\text { a trained reader } \\
\text { Direct ophthalmoscopy or indirect slit- } \\
\text { lamp fundoscopy through dilated pupil, or } \\
\text { Digital fundus photography }\end{array}$ \\
\hline ADA $2014^{11}$ & $\begin{array}{l}\text { Consider initial dilated and } \\
\text { comprehensive eye examination at } \\
\text { start of puberty or at age 10, whichever } \\
\text { is earlier, and after } 5 \text { years of type } 1 \\
\text { diabetes duration. }\end{array}$ & $\begin{array}{l}\text { Annual screening. May increase to } \\
\text { biennial eye exams if no findings } \\
\text { on screening. } \\
\text { If evidence of retinopathy is seen, } \\
\text { then resume annual exams. }\end{array}$ & High-quality fundus photographs. \\
\hline
\end{tabular}

ISPAD, International Society of Pediatric and Adolescent Diabetes; IDF, International Diabetes Federation; CDA, Canadian Diabetes Association; ADA, American Diabetes Association.

who develop diabetes before puberty; however the long term pre-pubertal years add to its cumulative prevalence. DR is generally infrequent and mild during childhood and may be related to the shorter length of time of glycemic exposure. ${ }^{9}$

In terms of screening methods, ADA, CDA and IDF/ISPAD guidelines $^{5,10,11}$ support fundus photography, with or without pupil dilation, as the method of screening for retinopathy. Nevertheless, ISPAD/IDF recognizes that this method may only be available in countries with ample resources, and thus it accepts dilated ophthalmoscopy as the minimum assessment. ${ }^{10}$ CDA specifies 7-field stereoscopic fundal photography as the gold standard for DR screening. ${ }^{5}$ (Table 2)

Moreover, ISPAD/IDF advocates the onset of screening at age 11 years while CDA promotes later initiation of screening at 15 years of age and after 5 years of diabetes duration. ${ }^{10}$ Table 3

This present survey highlights the lack of consistency both in the methods applied for retinopathy assessment as well as the time-intervals recommended by different specialists.

The divergent responses of this survey are a reflection of the different practices recommended by different expert groups. For example, ADA, CDA and ISPAD/IDF guidelines suggest annual DR screening, although there is no agreement on the age and duration of diabetes at initiation of screening. ${ }^{7}$ (Table 3)
In our survey, $94.7 \%$ of respondents, met the minimum recommendations and provided at least dilated ophthalmoscopy or fundal photography. Fundal photography was used by $34.2 \%$ of respondents, 9 respondents used it in combination with dilated ophthalmoscopy. Dilated ophthalmoscopy alone was used by $55.3 \%$.

Only less than $1 \%$ of our participants, all of whom were optometrists, apply the gold standard screening of 7-field fundal photography. Although it is not possible to confirm participant location, one explanation could be that these participants are linked to tertiary centres where higher resources are available.

The main limitation of this study is a low survey response rate which may not have captured the true prevalence of methods used for retinopathy screening and the communication gap between professionals.

Caring for children and adolescents with T1DM requires a multidisciplinary approach. Communication between healthcare members is crucial for optimal diabetes care and prevention of acute and chronic complications. CDA guidelines have no clear recommendations in relation to communication between specialists. ADA suggests that results of eye examinations should be documented and transmitted to 
the referring health care professional. Of note, almost $40 \%$ of optometrists in this survey report only to family doctors with no routine communication with the endocrinologist. Also, 3\% of the participants do not report to any physician involved in the care of these children.

In summary, this local survey demonstrated a broad range of screening methods for assessment of diabetic retinopathy with no consistency in relation to age of onset or frequency of eye examinations. It also identified a gap in communication between healthcare providers involved in the care of children and adolescents with T1DM. This highlights the need for improved communication in a timely manner in order to prevent the development of diabetes-related complications.

Acknowledgements: We thank Dr. Harry Van Ymeren OD, FAAO local optometrist for his invaluable assistance to this study.

\section{References}

1. Public Health Agency of Canada. Diabetes in Canada: Facts and figures from a public health perspective, downloaded from http://www.phac-aspc. gc.ca/cd-mc/publications/diabetes-diabete/facts-figures-faits-chiffres-2011/ highlights-saillants-eng.php\#chp5 .

2. Klein R, Klein BE, Moss SE, Davis MD, DeMets DL. The Wisconsin Epidemiologic Study of Diabetic Retinopathy: II. Prevalence and risk of diabetic retinopathy when age at diagnosis is less than 30 years. Archives of Ophthalmology1984; 102(4), 520-526.

3. Downie E, Craig M, Hing S, Cusumano J, Chan A, Donaghue K. Continued reduction in the prevalence of retinopathy in adolescents with type 1 diabetes: role of insulin therapy and glycemic control. Diabetes Care 2011; 34(11), 2368-2373.

4. CTDR Group, Complications Trial DCCT Research. Effect of intensive diabetes management on macrovascular events and risk factors in the Diabetes Control and Complications Trial. The American Journal of Cardiology 1995; 75.14: 894-903.

5. Boyd SR, Advani A, Altomare F, Stockl F. Canadian Diabetes Association 2013 Clinical Practice Guidelines for the Prevention and Management of Diabetes in Canada: retinopathy. Can J Diabetes 2013; 37 (Suppl 1):S137-S141
6. Younis N, Broadbent DM, Vora JP. Incidence of sight-threatening retinopathy in patients with type 2 diabetes in the Liverpool Diabetic Eye Study: a cohort study Lancet 3612003195200.

7. Donaghue KC, Chiarelli F, Trotta D, Allgrove J. and Dahl-Jorgensen K. Microvascular and macrovascular complications associated with diabetes in children and adolescents. Pediatric Diabetes 2009; 10: 195-203. doi: 10.1111/j.1399-5448.2009.00576.x.

8. Kubin M, Tossavainen P, Hannula V, Lahti S, Hautala N, Falck A. Prevalence of retinopathy in Finnish children and adolescents with type 1 diabetes: a cross-sectional population-based retrospective study. Archives of disease in childhood 2011 96.10, 963-968.

9. Porta M, Schellino F, Montanaro M, Baltatescu A, et al. Prevalence of retinopathy in patients with type 1 diabetes diagnosed before and after puberty.; Acta diabetologica 2014; 51.6 : 1049-1054.

10. International Diabetes Federation. Global IDF/ISPAD Guideline for Diabetes in Childhood and Adolescence. 2011;. Accessed March 6, 2015. https://www. ispad.org/content/2011-global-idfispad-guideline-diabetes-childhood-andadolescence.

11. American Diabetes Association. Standards of Medical Care in Diabetes. Diabetes Care 2014:37(Suppl 1):S14-S80.

12. Early Treatment Diabetic Retinopathy Study Research Group. Grading diabetic retinopathy from stereoscopic color fundus photographs: an extension of the modified Airlie House classification. ETDRS report number 10. Ophthalmology. 1991; 98:786- 806.

13. Gangaputra S T. Almukhtar AR. Glassman LP. Aiello N. Bressler SB. Bressler R.P. et al. Comparison of Film and Digital Fundus Photographs in Eyes of Individuals with Diabetes Mellitus. Investigative Ophthalmology \& Visual Science, 2011; 6168-173.

14. Flanagan J. Prokopich C. Indirect Fundus Biomicroscopy. Ophthalmic and Physiological Optics 1995; 15(2), S38-41.

15. Ahmed J. Ward TP. Bursell SE. Aiello LM. Cavallerano JD. Vigersky RA. The Sensitivity and Specificity of Nonmydriatic Digital Stereoscopic Retinal Imaging in Detecting Diabetic Retinopathy. Diabetes Care (2006) 29: 2205209.

16. Prasad S. Kamath GG, Jones K. Clearkin LG. Phillips RP. Effectiveness of Optometrist Screening for Diabetic Retinopathy Using Slit-lamp Biomicroscopy. Eye 2001; 15: 595-601.

17. Silva PS, Cavallerano JD, Sun JK, Noble J, Aiello LM, Aiello LP. Nonmydriatic Ultra wide Field Retinal Imaging Compared With Dilated Standard 7-Field 35-mm Photography and Retinal Specialist Examination for Evaluation of Diabetic Retinopathy. American Journal of Ophthalmology. 2012; 154(3):549-559. doi:10.1016/j.ajo.2012.03.019. 